\title{
Optimization of laccase production by Pycnoporus sanguineus in submerged liquid culture
}

\author{
S. B. Pointing ${ }^{1}$ \\ Centre for Research in Fungal Diversity, Department of \\ Ecology and Biodiversity, The University of Hong \\ Kong, Pokfulam Road, Hong Kong \\ E. B. G. Jones \\ L. L. P. Vrijmoed

\begin{abstract}
Department of Biology and Chemistry, City University of Hong Kong, Tat Chee Avenue, Kowloon, Hong Kong
\end{abstract}

Abstract: The white-rot fungus Pycnoporus sanguineus produces laccase under a range of $\mathrm{C} / \mathrm{N}$ ratios in submerged liquid culture. Enzyme production was increased 50 fold in the presence of $20 \mu \mathrm{M}$ xylidine to a maximum of $1368 \mathrm{U} \mathrm{L}^{-1}$ in a high carbon low nitrogen medium. Slight repression of enzyme production was observed in high nitrogen culture medium. Other potential inducers were less effective (Tween 80, wood fibres) and reduced the stimulation observed by xylidine alone when included in the same culture medium. Veratryl alcohol failed to stimulate laccase production. Activity of the enzyme activity in crude culture filtrate was stable at temperatures of $35 \mathrm{C}$ and below with a pH optimum of 3.0. The laccase of $P$. sanguineus was identified as a ca 65 $\mathrm{kDa}$ protein produced as multiple isoforms.

Key Words: Basidiomycete, laccase, Pycnoporus sanguineus, white-rot fungus

\section{INTRODUCTION}

Lignin is a highly recalcitrant compound, forming the second most abundant biopolymer in nature after cellulose. Degradation of lignin therefore represents a rate limiting step in carbon flux within environments rich in lignified cell walls. The mineralization of lignin is achieved appreciably only by the white-rot fungi. Most are members of the Basidiomycotina although some higher ascomycetes also cause white-rot (Worral et al 1997).

Enzymes involved in the degradation of lignin oxidize phenolic structures and catalyse the generation of highly reactive radicals that can also degrade non-

Accepted for publication August 27, 1999.

${ }^{1}$ Email: pointing@hkucc.hku.hk phenolic structures in lignins (Boominathan and Reddy 1992, Thurston 1994). The three classes of extracellular lignin modifying enzymes (LME) generally recognized are lignin peroxidase (E.C. 1.11.1.14) (LiP), Mn dependant peroxidase (E.C. 1.11.1.15) $(\mathrm{MnP})$ and laccase (E.C. 1.10.3.2) (Lcc). White-rot fungi variously produce one, two or all three of these phenoloxidase enzymes and this appears to be a ubiquitous feature among this group of fungi (Orth et al 1993). However most research to date has focused on relatively few species, notably Phanerochaete chrysosporium. This fungus secretes $\mathrm{LiP}$ and $\mathrm{MnP}$ as the dominant LME (Reddy and D'Souza 1994), where both enzymes are inducible under specific conditions of low nutrient nitrogen, high oxygen tension, presence of the inducer veratryl alcohol and static cultivation. Laccase is produced in small titres only under nitrogen sufficient conditions (Srinivasan et al 1995). Studies on other fungi have revealed different LME production profiles and physiology (Nerud et al 1991, Orth et al 1993). Most notably that Lcc activity is generally greater than that of either LiP or MnP in most strains studied (Collins and Dobson 1997, Eggert et al 1996b). This makes Lcc producing fungi particularly good candidates for biotechnological applications employing LME, such as biobleaching, biopulping and bioremediation (Reddy 1995).

Most studies on Lcc producing fungi have used temperate strains whereas tropical white-rot fungi have received relatively little attention in comparison. The basidiomycete Pycnoporus sanguineus is widely distributed on lignocellulose in tropical forests (Almeida-Filho et al 1993, Gazzano 1990, Ribeiro and Aguiar 1993) and is associated with aggressive whiterot type decay. Here we report on the physiology of LME production by this fungus, in particular attempts to optimize enzyme secretion.

\section{MATERIALS AND METHODS}

Organism and cultivation.-The $P$. sanguineus strain CY788 used in this study was isolated from decaying wood in Thailand. Stocks were maintained on malt extract agar slopes (Difco) with periodic transfer. The fungus was identified as potentially ligninolytic by clearance of agar plates [glucose $0.2 \%(\mathrm{w} / \mathrm{v})$, mycological peptone (Oxoid) $0.01 \%(\mathrm{w} / \mathrm{v})$, yeast extract (Difco) $0.001 \%(\mathrm{w} / \mathrm{v})$, agar $1.4 \%(\mathrm{w} / \mathrm{v})]$ supplemented with $0.02 \%$ (w/v) Poly-R (Poly R478, Sigma). 
For production of inoculum the fungus was grown on malt extract agar (Difco) plates for $7 \mathrm{~d}$ at $25 \mathrm{C}$ in darkness. A whole plate culture was then aseptically transferred to a sterilized Waring blender cup and homogenized with 50 $\mathrm{mL}$ distilled water at low speed for $3 \times 10 \mathrm{~s}$. Aliquots of 0.5 $\mathrm{mL}$ were then transferred to 250-mL Erlenmyer flasks. Each flask contained $25 \mathrm{~mL}$ of a defined growth medium consisting of ( $\mathrm{g} \mathrm{L}^{-1}$ unless indicated) : 2,2-dimethylsuccinic acid, 1.46; nitrilotriacetate, $0.15 ; \mathrm{KH}_{2} \mathrm{PO}_{4}, 2 ; \mathrm{MgSO}_{4} \cdot 7 \mathrm{H}_{2} \mathrm{O}, 0.5$; $\mathrm{CaCl}_{2} \cdot 2 \mathrm{H}_{2} \mathrm{O}, 0.1 ; \mathrm{MnSO}_{4} \cdot 5 \mathrm{H}_{2} \mathrm{O}, 5 \mathrm{mg} ; \mathrm{NaCl}, 10 \mathrm{mg}$; $\mathrm{FeSO}_{4} \cdot 7 \mathrm{H}_{2} \mathrm{O}, 1 \mathrm{mg} ; \mathrm{CoCl}_{2} \cdot 6 \mathrm{H}_{2} \mathrm{O}, 1 \mathrm{mg} ; \mathrm{ZnSO}_{4} \cdot 7 \mathrm{H}_{2} \mathrm{O}, 1 \mathrm{mg}$; $\mathrm{CuSO}_{4} \cdot 5 \mathrm{H}_{2} \mathrm{O}, 0.1 \mathrm{mg} ; \mathrm{AlK}\left(\mathrm{SO}_{4}\right)_{2}, 0.1 \mathrm{mg} ; \mathrm{H} 3 \mathrm{BO}_{3}, 0.1 \mathrm{mg}$; $\mathrm{NaMoO}_{4} \cdot 2 \mathrm{H}_{2} \mathrm{O}, 0.1 \mathrm{mg}$; thiamine $\cdot \mathrm{HCl}, 1 \mathrm{mg}$; glucose as carbon source (0.1-1.2 $\mathrm{g} \mathrm{L}^{-1}$ as detailed in the text); ammonium tartrate as nitrogen source $(0.24-48 \mathrm{mM}$ as detailed in the text). In some experiments the growth medium was supplemented with yeast extract, $1 \mathrm{mg} \mathrm{L}^{-1}$; Tween 80 , $0.05 \% \mathrm{w} / \mathrm{v}$; veratryl alcohol (3,4, dimethoxybenzoic acid), 1-4 mM; xylidine (2, 5,-dimethylanilline), 5-100 $\mu \mathrm{M}$; milled and sieved wood (Fagus sylvatica) particles $(250-500 \mu \mathrm{m})$, $1 \% \mathrm{w} / \mathrm{v}$, as indicated in the text. Final $\mathrm{pH}$ of growth medium in all experiments was 4.5. All cultivations were carried out at $25 \mathrm{C}$ on a rotary shaker $(125 \mathrm{rpm})$ with triplicate flasks for each treatment.

Enzyme assays.-Extracellular culture fluids were assayed for enzyme activity after mycelium was removed by centrifugation $(30 \mathrm{~s}$ at $10000 \mathrm{~g}$ ). Lcc activity was determined by

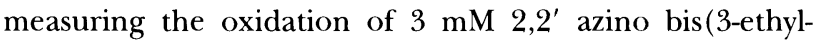
benzthiazoline-6-sulfonic acid) (ABTS) in glycine-HCl buffer $\left(\mathrm{pH} \mathrm{3.0)}\right.$ at $420 \mathrm{~nm}\left(\epsilon \max =3.6 \times 10^{4} \mathrm{M}^{-1} \mathrm{~cm}^{-1}\right)$ and $35 \mathrm{C}$. In some experiments culture supernatant was preincubated with catalase $\left(1000\right.$ units $\mathrm{mL}^{-1}$ ) (E.C. 1.11.1.6 from Aspergillus niger, Sigma C3515) for $30 \mathrm{~min}$ at $30 \mathrm{C}$ prior to assay in order to remove any endogenous $\mathrm{H}_{2} \mathrm{O}_{2}$. In some experiments glycine-HCl buffer was replaced with a sodium acetate or sodium tartrate buffer.

Manganese independent peroxidase activity was measured by adding $\mathrm{H}_{2} \mathrm{O}_{2}$ (1 $\mathrm{mM}$ final concentration) to the laccase assay mixture and subtracting the activity due to laccase alone. Lignin peroxidase activity was determined by measuring the production of veratraldehyde from veratryl alcohol at $310 \mathrm{~nm}\left(\epsilon \max =9300 \mathrm{M}^{-1} \mathrm{~cm}^{-1}\right)$ in glycine- $\mathrm{HCl}$ buffer $(\mathrm{pH} 3.0)$ at $30 \mathrm{C}$, upon addition of $\mathrm{H}_{2} \mathrm{O}_{2}(1 \mathrm{mM}$ final concentration). Aryl alcohol oxidase was assayed under the same conditions without the addition of $\mathrm{H}_{2} \mathrm{O}_{2}$. Manganese dependant peroxidase activity was measured by the oxidation of phenol red at $431 \mathrm{~nm}\left(\epsilon \max =22000 \mathrm{M}^{-1}\right.$ $\mathrm{cm}^{-1}$ ) in the presence of $100 \mu \mathrm{M} \mathrm{MnSO} \mathrm{M}_{4} \cdot 5 \mathrm{H}_{2} \mathrm{O}$ in glycine$\mathrm{HCl}$ buffer $(\mathrm{pH} 3.0)$ at $30 \mathrm{C}$, upon addition of $\mathrm{H}_{2} \mathrm{O}_{2}(0.5$ $\mathrm{mM}$ final concentration).

All enzyme assays were carried out using a Hewlett-Packard 8452A UV-visible diode array spectrophotometer. Enzyme activities were expressed as units, with one unit defined as that forming $1 \mu$ mole product $\min ^{-1}$. All values reported are the mean of three replicates, with standard error of the mean (SE) represented by error bars. Where SE falls within the data point symbols error bars have been omitted.
Protein and biomass determination.-Protein was determined using the method of Lowry et al (1951) using bovine serum albumin as the standard. Fungal biomass was determined by filtering mycelium through three layers of cheesecloth, washing with distilled water, and drying at $105 \mathrm{C}$ overnight.

Determination of molecular weight and isozyme banding pattern.-SDS PAGE was performed as described by Bollag and Edelstein (1992) on crude culture filtrates concentrated 100 fold by centrifugation using a $10 \mathrm{kDa}$ cut-off filter (Ultrafree 15, Millipore). Samples were run with Sigmamarkers wide range protein standards (Sigma M4038), and protein bands visualized using coomassie blue staining. Molecular weight of the laccase band was calculated from relative mobility compared to standards. Nondenaturing PAGE was carried out as described by Bollag and Edelstein (1992). Samples were run and lacase bands detected by staining with $0.05 \%(\mathrm{w} / \mathrm{v})$ ABTS.

\section{RESULTS}

In preliminary experiments strains of $P$. sanguineus were grown on agar plates containing $0.02 \%(\mathrm{w} / \mathrm{v})$ Poly-R. The strain used in this study was chosen for its ability to rapidly decolorize the dye, which is indicative of LME production (Boominathan and Reddy 1992). Initial experiments in submerged liquid culture revealed superior growth and Lcc production in shaken rather than static or static-oxygen purged conditions (data not shown) and so all subsequent experiments were carried out in shake culture. No LiP, MnP, manganese independant peroxidase or aryl alcohol oxidase activity was detected in any cultivation despite inclusion in the growth medium of the inducer veratryl alcohol (1-4 mM) and static oxygenpurged cultivation, conditions known to favour peroxidase enzyme production in Phanerochaete chrysosporium (Reddy and D'Souza 1994).

The Lcc activity of $P$. sanguineus culture filtrates produced linear reaction rates at enzyme assay temperatures up to $40 \mathrm{C}$. The enzyme was very stable at $4 \mathrm{C}$, with no significant loss in activity over $8 \mathrm{~h}$. At temperatures of $35 \mathrm{C}$ and below the enzyme was stable over $60 \mathrm{~min}$, with rapid loss in activity occuring after relatively short periods at higher temperatures. A single distinct $\mathrm{pH}$ optima of 3.0 was recorded for Lcc activity in culture filtrates. The glycine-HCL buffer used gave higher enzyme activities than sodium tartrate or sodium acetate buffers and so was used in all subsequent experiments (data not shown).

The effect of different carbon (as glucose) and nitrogen (as ammonium tartrate) concentrations in the growth medium on enzyme production were determined (TABLE I). From this data 'low' and 'high' carbon $[0.2 \%(\mathrm{w} / \mathrm{v}), 0.8 \%(\mathrm{w} / \mathrm{v})]$ and nitrogen $(2.4 \mathrm{mM}$ and $24 \mathrm{mM}$ ) concentrations were selected for use in further experiments. Laccase was produced consti- 
TABLE I. Influence of growth medium carbon and nitrogen levels on laccase production by $P$. sanguineus

\begin{tabular}{cccc}
\hline \hline $\begin{array}{c}\text { Glucose } \\
(\% \mathrm{w} / \mathrm{v})^{\mathrm{a}}\end{array}$ & $\begin{array}{c}\text { Relative } \\
\text { laccase } \\
\text { production } \\
(\%)^{\mathrm{b}}\end{array}$ & $\begin{array}{c}\text { Ammonium } \\
\text { tartrate } \\
(\mathrm{mM})^{\mathrm{c}}\end{array}$ & $\begin{array}{c}\text { Relative } \\
\text { laccase } \\
\text { production } \\
(\%)^{\mathrm{b}}\end{array}$ \\
\hline 0.1 & 26 & 0.24 & 6 \\
0.2 & 90 & 2.40 & 100 \\
0.4 & 92 & 12.00 & 94 \\
0.8 & 100 & 24.00 & 86 \\
1.2 & 73 & 48.00 & 56 \\
\hline
\end{tabular}

a With $2.4 \mathrm{mM}$ ammonium tartrate.

${ }^{b}$ Values reported for 7 day old incubations.

c With $0.2 \% \mathrm{w} / \mathrm{v}$ glucose.

tutively in liquid culture under all conditions tested. Activity was detectable after $2 \mathrm{~d}$ and reached a peak after $7 \mathrm{~d}$ cultivation. Optimum Lcc production in non-induced cultures was $22 \mathrm{U} \mathrm{L}^{-1}$. Veratryl alcohol failed to stimulate Lcc production.

Enzyme production was however increased upon addition of the known laccase inducer xylidine (Eggert et al 1996a) (FIG. 1). Stimulation was observed at concentrations from $10-100 \mu \mathrm{M}$, with optimum induction about 50 fold $\left(22 \mathrm{U} \mathrm{L}^{-1}\right.$ to $\left.1140 \mathrm{U} \mathrm{L}^{-1}\right)$ by the addition of $20 \mu \mathrm{M}$ xylidine. Lower levels of inducer resulted in less stimulation of activity. Similarly xylidine levels greater than $20 \mu \mathrm{M}$ resulted in reduced stimulation.

The $\mathrm{C} / \mathrm{N}$ ratio of culture medium has been reported to affect peroxidase enzyme production (Reddy and D'Souza 1994) and so the effect of different $\mathrm{C} / \mathrm{N}$ ratios on xylidine induced cultures was assessed (FIG. 2). Optimum enzyme production (1368 $\left.\mathrm{U} \mathrm{L}^{-1}\right)$ was achieved in high carbon low nitrogen conditions, although lowest enzyme production $\left(378 \mathrm{U} \mathrm{L}^{-1}\right)$ corresponding to a $72 \%$ decrease was recorded in high carbon high nitrogen cultures. In low carbon cultures only slight repression (14\%) of Lcc production was observed under high nitrogen conditions. The specific activity of Lcc in cultures varied; low carbon low nitrogen, $4.2 \pm 0.0$; low carbon high nitrogen, $2.5 \pm 0.06$; high carbon low nitrogen, $2.0 \pm 0.04$; high carbon high nitrogen, $0.86 \pm 0.27$.

Further experiments were carried out using high carbon low nitrogen growth medium to optimize enzyme production by including other potential inducers of Lcc activity (FIG. 3). The addition of $0.05 \%$ (w/ v) Tween 80 to non induced cultures resulted in a 3 fold stimulation of activity from $22 \mathrm{U} \mathrm{L}^{-1}$ to $60 \mathrm{U} \mathrm{L}^{-1}$. However when added to xylidine induced cultures optimum enzyme production was reduced from 1368 $\mathrm{U} \mathrm{L}^{-1}$ to $914 \mathrm{U} \mathrm{L}^{-1}$. Similarly addition of a $1 \%(\mathrm{w} /$ v) wood co-substrate enhanced laccase production 12

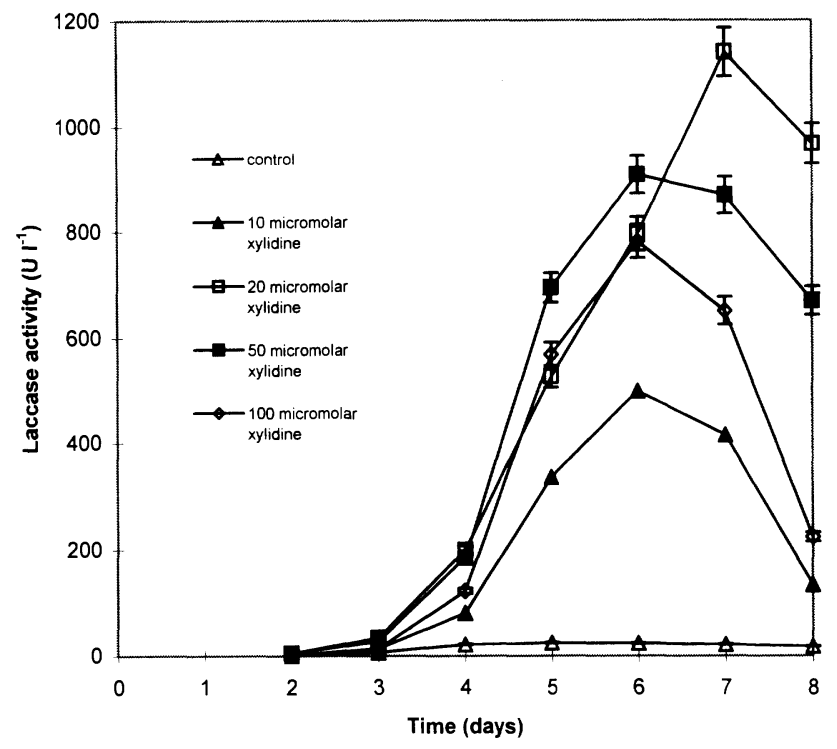

FIG. 1. Stimulation of laccase production by $P$. sanguineus in cultures containing $0.2 \% \mathrm{w} / \mathrm{v}$ glucose, $2.4 \mathrm{mM}$ ammonium tartrate and various amounts of xylidine. Data points represent the mean of three independant replicates. SE falls within data point symbols unless indicated by error bars.

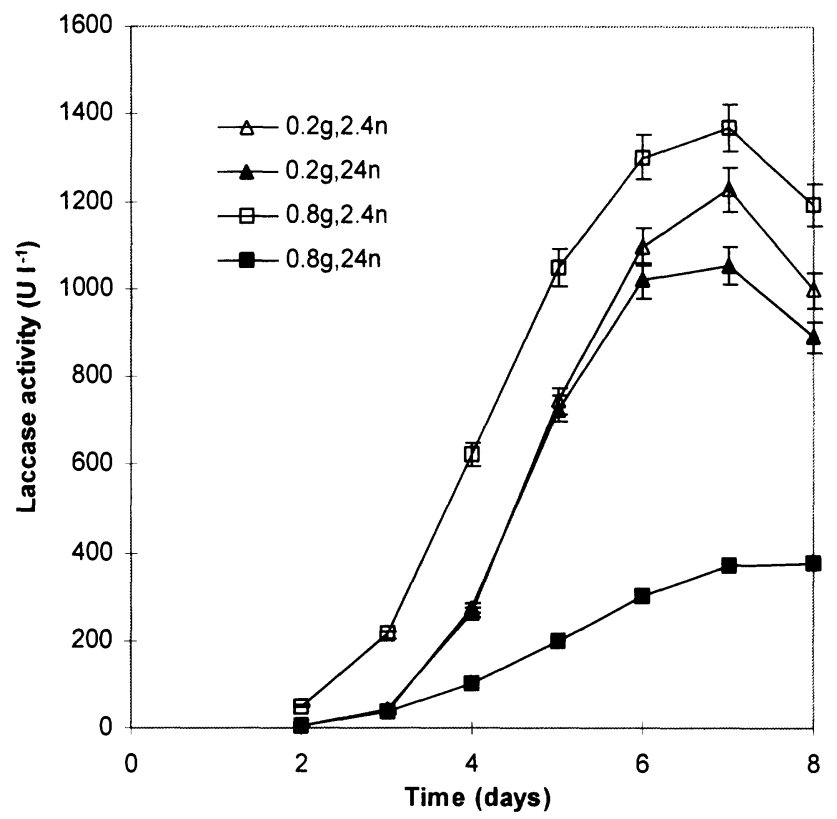

FIG. 2. Effect of $\mathrm{C} / \mathrm{N}$ ratio on laccase production by $P$. sanguineus in cultures containing $20 \mu \mathrm{M}$ xylidine. $0.2 \mathrm{~g} 2.4$ $\mathrm{n}=0.2 \% \mathrm{w} / \mathrm{v}$ glucose, $2.4 \mathrm{mM}$ ammonium tartrate; $0.2 \mathrm{~g}$ $24 \mathrm{n}=0.2 \% \mathrm{w} / \mathrm{v}$ glucose, $24 \mathrm{mM}$ ammonium tartrate; 0.8 g $2.4 \mathrm{n}=0.8 \% \mathrm{w} / \mathrm{v}$ glucose, $2.4 \mathrm{mM}$ ammonium tartrate; $0.8 \mathrm{~g} 24 \mathrm{n}=0.8 \% \mathrm{w} / \mathrm{v}$ glucose, $24 \mathrm{mM}$ ammonium tartrate Data points represent the mean of three independant replicates. SE falls within data point symbols unless indicated by error bars. 


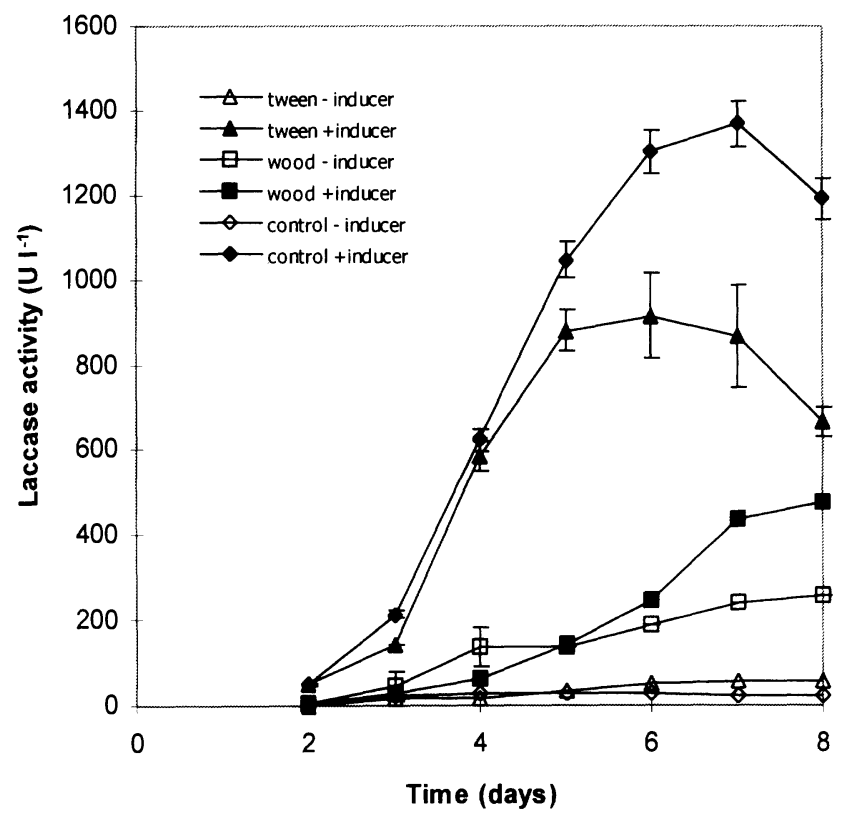

FIG. 3. Effect of the addition of Tween $80(0.05 \% \mathrm{w} / \mathrm{v})$ and Fagus sylvatica wood particles $(1 \% \mathrm{w} / \mathrm{v})$ on laccase production by $P$. sanguineus in cultures grown in $0.8 \% \mathrm{w} / \mathrm{v}$ glucose, $2.4 \mathrm{mM}$ ammonium tartrate and in the absence (open symbols) and presence (closed symbols) of $20 \mu \mathrm{M}$ xylidine. Data points represent the mean of three independant replicates. SE falls within data point symbols unless indicated by error bars.

fold to $257 \mathrm{U} \mathrm{L}^{-1}$ whereas inclusion of wood in xylidine induced cultures reduced optimum enzyme production almost 3 fold to $477 \mathrm{U} \mathrm{L}^{-1}$.

Electrophoresis of proteins in glucose-grown culture filtrates clearly revealed a single protein band of ca $65 \mathrm{kDa}$ after SDS PAGE (FIG. 4A). Appearance and staining intensity of the band could be correlated with Lcc activity of cultures although, in wood-supplemented cultures multiple banding patterns made visualization of a band corresponding to Lcc production difficult (FIG. 4A). Other (non-Lcc) bands observed in wood-supplemented culture filtrates were probably enzymes associated with utilization of the complex wood substrate. Activity staining of non-denaturing gels suggests glucose-grown cultures of $P$. sanguineus produce two isoforms of the $65 \mathrm{kDa} \mathrm{Lcc}$ protein (FIG. 4B). The stronger staining isoform was designated Lccl and the weaker staining isoform Lcc2. Cultures supplemented with wood produced only a single Lcc isoform (FIG. 4B). This appeared distinct from either Lcc1 or Lcc2 and so was designated Lcc3.

\section{DISCUSSION}

Pycnoporus sanguineus is a fungus commonly associated with aggressive white-rot type wood decay in tropical climates. In this study Lcc was produced under a variety of culture conditions by this fungus including cultures supplemented with a native wood substrate. Optimum conditions for Lcc production appear to be different from those reported as necessary for other LMEs, notably LiP and MnP in other fungi (Reddy and D'Souza 1994). No LiP, MnP, Mn independent peroxidase or aryl alcohol oxidase was detected in cultures of $P$. sanguineus used in this study under conditions known to favour induction of such enzymes (defined nutrient-limited media, static oxygen-purged cultivation, presence of veratryl alcohol). However it is possible that this fungus may possess peroxidase enzymes requiring as yet unidentified conditions for induction.

Laccase activity was enhanced 50 fold by the addition of $20 \mu \mathrm{M}$ xylidine to cultures, this is the most significant effect of this inducer in stimulating laccase activity reported for any fungus to date. The maximum level of laccase stimulation previously recorded for this inducer is 10 fold for a strain of Pycnoporus cinnabarinus (Eggert et al 1996b). The reduced stimulation observed at higher concentrations of xylidine in this study may be due to toxic effects of xylidine on the fungus. The Lcc of $P$. sanguineus in this study was not stimulated by veratryl alcohol, although in $P$. cinnabarinus this compound is reported to increase Lcc production 2-3 fold (Eggert et al 1996b, Kantelinen et al 1989). The reason for the reduced stimulation of Lcc production in xylidine induced cultures supplemented with Tween 80 is not clear. In studies with Phlebia radiata the addition of Tween 80 to veratryl alcohol induced cultures has resulted in increased enzyme production (Kantelinen et al 1989).

The stimulation of Lcc production 12 fold by the addition of wood fibres to non-induced cultures suggests that this fungus could be grown effectively on waste lignocellulose substrates to achieve lignin biodegradation. The enzyme production levels reported by the strain of $P$. sanguineus used in this study are over 3 fold higher than those previously reported for $P$. sanguineus grown on Eucalyptus grandis wood chips (Esposito et al 1993). The tropical distribution of this fungus may also make it a particularly good candidate for use in the biotransformation of lignocellulosic wastes such as sago-hampas, cocopeat and bagasse which are produced in large quantities in tropical regions. One study has already shown laccase production by $P$. sajor-caju grown on sago-hampas (Kumaran et al 1997).

Optimal Lcc production by $P$. sanguineus was 1368 $\mathrm{U} \mathrm{L} \mathrm{L}^{-1}$, this is higher than that reported for many other basidiomycetes cultured under similar conditions (Orth et al 1993, Kantelinen et al 1989, Srini- 


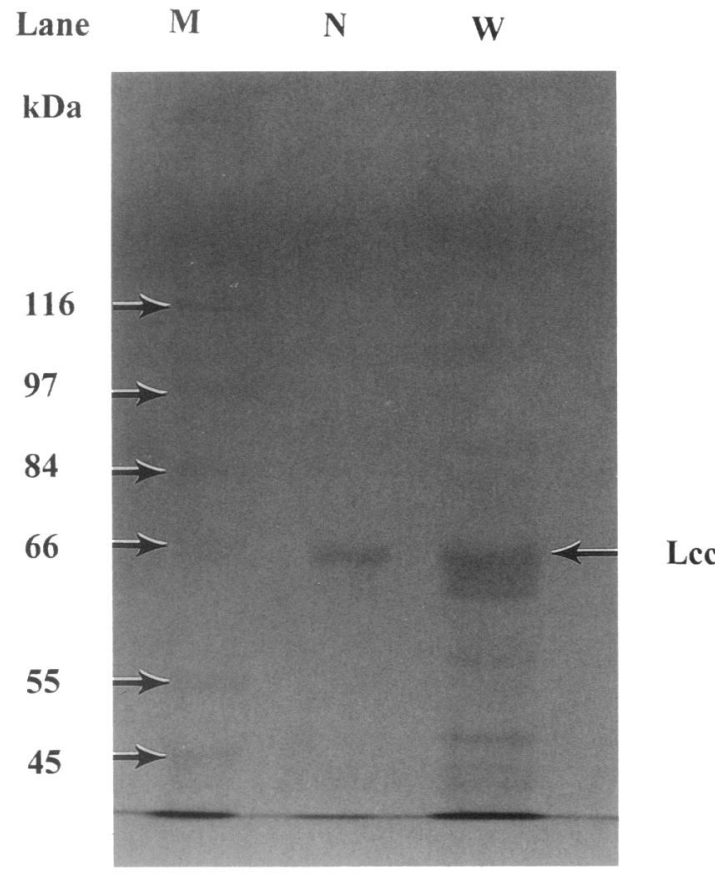

A

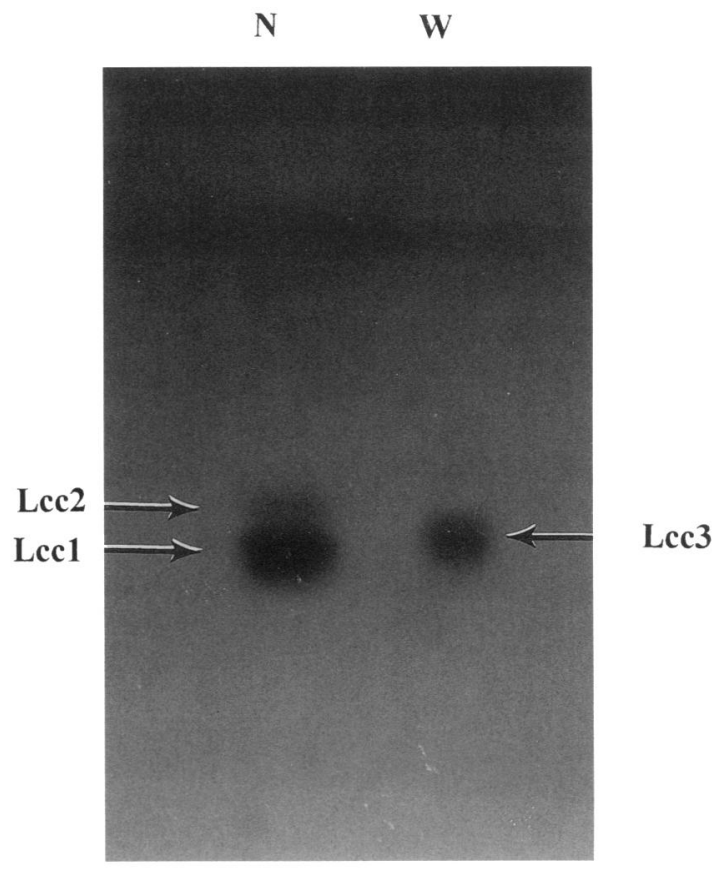

B

FIG. 4. SDS PAGE (A) and ND PAGE (B) of $P$. sanguineus culture filtrate $(\times 100$ fold concentrate). A. Cultures grown in fully defined nutrient medium displayed a single protein band of mol. wt. ca $65 \mathrm{kDa}$ corresponding to laccase production (lane $\mathrm{N}$, arrowed). Cultures supplemented with wood produced multiple bands in the mw region expected for fungal laccases (lane W). Molecular weight markers used (lane M) were Sigmamarkers wide range (Sigma). B. Activity staining of gels revealed two isoforms produced in fully defined growth medium. The more intensely stained isoform was designated Lcc1, whilst the weaker staining isoform was labelled Lcc2. Cultures supplemented with wood produced a single laccase isoform. This appeared to be distinct from Lcc1 and Lcc2 and so was designated as Lcc3.

vasan et al 1995) although it is not clear if such conditions were optimal for each fungus. Conversely few strains are reported to produce Lcc at greater levels than those recorded for $P$. sanguineus in this study under similar growth conditions. Notable exceptions are Trametes versicolor $\left(5000 \mathrm{U} \mathrm{L}^{-1}\right)$ (Collins and Dobson 1997) and Pleurotus sajor-caju $\left(4000 \mathrm{U} \mathrm{L}^{-1}\right)(\mathrm{Bu}-$ swell et al 1996).

Previous studies among species of Pycnoporus are sparse and reveal varied data. The previously reported maximum Lcc activity for $P$. sanguineus is $88.7 \mathrm{U}$ $\mathrm{L}^{-1}$ in a malt-extract growth medium (Esposito et al 1993). In contrast to the results reported here this study also identified MnP activity and a Mn independent peroxidase activity in culture filtrates, although LiP was not detected. LME production by $P$. cinnabarinus has been studied in more detail. Optimum Lcc production by this fungus was $10000 \mathrm{U} \mathrm{L}^{-1}$ (Eggert et al 1996b). No LiP or MnP were detected, but very low levels of a $\mathrm{Mn}$ independent peroxidase were produced. The purified Lcc from $P$. cinnabarinus has further been shown as essential for lignin degradation by this fungus (Eggert et al 1996a, 1997). Laccase was also reported from $P$. coccineus albeit at rel- atively lower levels (Oda et al 1991). The nature of the laccase proteins appears to vary greatly between different laccase producing genera however, the Lcc isoforms identified in this study approximate the molecular mass of Lcc from $P$. cinnabarinus and $P$. coccineus, although the number of isoforms reported in each case vary (Eggert et al 1996b, Oda et al 1991).

Laccase production in $P$. sanguineus was slightly repressed by high nitrogen levels in this study. This is a common feature in fungal $\mathrm{LiP}$ and $\mathrm{MnP}$ production (Reddy and D'Souza 1994) although Lcc responses appear to vary. The Lcc of $P$. cinnabarinus is also repressed slightly by high $(24 \mathrm{mM})$ nitrogen levels $(\mathrm{Eg}$ gert et al 1996b). Although optimum Lcc production in $T$. versicolor occurs in the presence of $54.3 \mathrm{mM}$ ammonium tartrate (Collins and Dobson 1997) and Lcc activity can only be detected in $P$. chrysosporium under high (24 $\mathrm{mM})$ nitrogen conditions albeit at very low levels (Srinivasan et al 1995). In this study Lcc production was further reduced under conditions of high nitrogen and high carbon. Since cultures grown in high carbon/low nitrogen media were the most active in producing Lcc, this repression was 
probably not due to glucose level but rather the overall condition of nutrient sufficiency.

It is the relative nonspecificity of ligninolytic enzymes in catalysing oxidative reactions that has generated interest in their biotechnological applications. Lignin peroxidase and $\mathrm{MnP}$ producing white-rot fungi have been demonstrated to decolorize industrial dyes and degrade several polycyclic aromatic hydrocarbons (Reddy 1995). With a greater understanding of Lcc physiology, fungi producing this enzyme are currently the focus of much attention, since Lcc production generally exceeds that of peroxidases. Lignin degradation (Eggert et al 1996b), Dye decolorization (Esposito et al 1993, Schliephake et al 1993), PCB (Ricotta et al 1996) and PAH degradation (Collins et al 1996, Majcherczyk et al 1998) have all been demonstrated by Lcc in the presence of a redox mediator. The white-rot fungus $P$. sanguineus seems a likely candidate for application in these areas.

\section{ACKNOWLEDGMENTS}

This work was funded by a Research Fellowship to one of the authors (SBP) granted by the Centre for Environmental Science and Technology, Department of Biology and Chemistry, City University of Hong Kong.

\section{LITERATURE CITED}

Almeida-Filho OMDA, Bueno R, Bononi VLR. 1993. Some basidiomycetes from mangrove in Sao Paulo State. Hoehnea 20:87-92.

Bollag DM, Edelstein SJ. 1992. Protein methods. 2nd ed. New York: John Wiley and Sons. 230 p.

Boominathan K, Reddy CA. 1992. Fungal degradation of lignin. In: Akora DK, Elander RP, Mukerji KG, eds. Handbook of applied mycology. Vol. 4: fungal biotechnology. New York: Marcel Dekker. p 763-882.

Buswell JA, Cai YJ, Chang ST, Perberdy JF, Fu SY, Yu H-S. 1996. Lignocellulolytic enzyme profiles of edible mushroom fungi. World J Microbiol Biotechnol 12:537-542.

Collins PJ, Dobson ADW. 1997. Regulation of gene transcription in Trametes versicolor. Appl Environ Microbiol 63:3444-3450.

— Kotterman MJJ, Field JA, Dobson ADW. 1996. Oxidation of anthracene and benzo $[a]$ pyrene by laccases from Trametes versicolor. Appl Environ Microbiol 62: 4563-4567.

Eggert C, Temp U, Dean JFD, Eriksson K-EL. 1996a. A fungal metabolite mediates degradation of non-phenolic lignin structures and synthetic lignin by laccase. FEBS Lett 391:144-148.

— — - Eriksson K-EL. 1996b. The ligninolytic system of the white-rot fungus Pycnoporus cinnabarinus; purification and characterization of the laccase. Appl Environ Microbiol 62:1151-1158.
1997. Laccase is essential for lignin degradation by the white-rot fungus Pycnoporus cinnabarinus. FEBS Lett 407:89-92.

Esposito E, Innocentini-Mei LH, Ferraz A, Canhos VP, Duran N. 1993. Phenoloxidases and hydrolases from $P y c$ noporus sanguineus (EUC-2050 strain): applications. J Biotechnol 29:219-228.

Gazzano S. 1990. Notes on xylophilous basidiomycetes from Uruguay: IV polyporaceae and hymenochaetaceae from a native forest in Montevideo Department. Commun Bot Mus Hist Natl Montevideo 5:1-4.

Kantelinen A, Hatakka A, Viikari L. 1989. Production of lignin peroxidase and laccase by Phlebia radiata. Appl Microbiol Biotechnol 31:234-239.

Kumaran S, Sastry CA, Vikineswary S. 1997. Laccase, cellulase and xylanase activities during growth of Pleurotus sajor-caju on sago hampas. World J Microbiol Biotechnol 13:43-49.

Lowry OH, Roseborough MJ, Farr AL, Randall RJ. 1951. Protein measurement with the Folin-Phenol reagent. J Biol Chem 193:265-275.

Majcherczyk A, Johannes C, Huttermann A. 1998. Oxidation of polycyclic aromatic hydrocarbons (PAH) by laccase of Trametes versicolor. Enz Microb Technol 22:335341.

Nerud F, Zouchova Z, Misurcova Z. 1991. Ligninolytic properties of different white-rot fungi. Biotechnol Lett 13: $657-660$.

Oda Y, Adachi K, Aita I, Ito M, Aso Y, Igarashi H. 1991. Production and properties of laccase secreted by Pycnoporus coccineus. Agric Biol Chem 55:1393-1395.

Orth AB, Royse DJ, Tien M. 1993. Ubiquity of lignin-degrading peroxidases among various wood-degrading fungi. Appl Environ Microbiol 59:4017-4023.

Reddy CA. 1995. The potential for white-rot fungi in the treatment of pollutants. Curr Opinion Biotechnol 6: 320-328.

—, D'Souza TM. 1994. Physiology and molecular biology of the lignin peroxidases of Phanerochaete chrysosporium. FEMS Microbiol Rev 13:137-152.

Ribiero MNS, Aguiar IDJA. 1993. Decomposing hymenomycetes of wood saw mills of Manaus, AM, Brasil. Acta Amazonica 23:219-225.

Ricotta A, Unz RF, Bollag J-M. 1996. Role of laccase in the degradation of pentachlorophenol. Bull Environ Contam Toxicol 57:560-567.

Schliephake K, Lonergan GT, Jones CL, Mainwaring DE. 1993. Decolorization of a pigment plant effluent by Pycnoporus cinnabarinus in a packed bed bioreactor. Biotechnol Lett 15:1185-1188.

Srinivasan C, D'Souza TM, Boominathan K, Reddy CA. 1995. Demonstration of laccase in the white-rot basidiomycete Phanerochaete chrysosporium BKM-F1767. Appl Environ Microbiol 61:4274-4277.

Thurston CF. 1994. The structure and function of fungal laccases. Microbiology 140:19-26.

Worral JJ, Anagnost SE, Zabel RA. 1997. Comparison of wood decay among diverse lignicolous fungi. Mycologia 89:199-219. 